\title{
Campos de Experiência e Demonstração do Estado de São Paulo Resgate documental nos Relatórios da Secretaria da Agricultura (1899-1914)
}

Experience and Demonstration Fields of the State of São Paulo

Documentary rescue in the Reports of the Secretariat of Agriculture (1899-1914)

Campos de Experiencia y Demostración del Estado de São Paulo Rescate documental en los Informes de la Secretaría de Agricultura (1899-1914)

Laís Bim Romero Mestranda, PPGARQ, UNESP, Brasil. lbimromero@gmail.com

Marta Enokibara Professora Doutora, PPGARQ, UNESP, Brasil marta.enokibara@unesp.br 


\section{RESUMO}

A Secretaria da Agricultura, Comércio e Obras Públicas (SACOP) do Estado de São Paulo criou o Serviço Agronômico, por meio da Lei $n^{\circ} 678$ de 13 de setembro de 1899, no intuito de organizar as incumbências relativas à agricultura. Esse Serviço baseava-se em quatro eixos principais: o ensino, a pesquisa, a diversificação agrícola e a criação de uma infraestrutura capaz de apoiar e subsidiar as outras três atividades. Objetiva-se com esse artigo resgatar a memoria documental relativa a essa infraestrutura, especificamente no que tange aos Campos de Experiência e Demonstração, criados para levar ao homem do campo informações sobre as técnicas mais modernas de agricultura e, ao mesmo tempo, determinar as melhores culturas a serem utilizadas nas diferentes regiões do Estado. Para tanto, por meio dos Relatórios Anuais da Secretaria da Agricultura, fontes primárias desta pesquisa, serão levantados quais eram esses Campos, quando foram criados, onde se localizavam e quais culturas ensaiavam; em um recorte temporal que se inicia em 1899, com criação do Serviço Agronômico, estendendo-se até 1914 quando, por medidas de economia a SACOP é reorganizada e alguns Campos são desativados.

PALAVRAS-CHAVE: Serviço Agronômico. Campos de Experiência e Demonstração. Relatórios da Secretaria da Agricultura, Comércio e Obras Públicas do Estado de São Paulo.

\section{ABSTRACT}

The São Paulo State Secretariat of Agriculture, Commerce and Public Works (SACOP) created the Agronomic Service, through Law 678 of September 13, 1899, in order to organize the tasks related to agriculture. This Service was based on four main axes: teaching, research, agricultural diversification and the creation of an infrastructure capable of supporting and subsidizing the other three activities. The purpose of this article is to retrieve the documentary memory related to this infrastructure, specifically with regard to the Fields of Experience and Demonstration, designed to bring the man of the field information on the most modern techniques of agriculture and, at the same time, to determine the best to be used in the different regions of the State. To do so, through the Annual Reports of the Secretariat of Agriculture, primary sources of this research, will be raised which were those Fields, when they were created, where they were located and what cultures were tested; in a temporal cut that began in 1899, with the creation of the Agronomic Service, extending until 1914 when, for economic measures SACOP is reorganized and some Fields are deactivated.

KEYWORDS: Agronomic Service. Fields of Experience and Demonstration. Reports from the Secretariat of Agriculture, Commerce and Public Works of the State of São Paulo.

\section{RESUMEN}

La Secretaría de Agricultura, Comercio y Obras Públicas (SACOP) del Estado de São Paulo creó el Servicio Agronómico, por medio de la Ley $\mathrm{n}^{\circ} 678$ de 13 de septiembre de 1899, con el fin de organizar las tareas relativas a la agricultura. Este Servicio se basaba en cuatro ejes principales: la enseñanza, la investigación, la diversificación agrícola y la creación de una infraestructura capaz de apoyar y subsidiar las otras tres actividades. Se pretende con este artículo rescatar la memoria documental relativa a esa infraestructura, específicamente en lo que se refiere a los Campos de Experiencia y Demostración, creados para llevar al hombre del campo informaciones sobre las técnicas más modernas de agricultura y, al mismo tiempo, determinar las mejores cultivos a utilizar en las diferentes regiones del Estado. Para ello, por medio de los Informes Anuales de la Secretaría de Agricultura, fuentes primarias de esta investigación, serán levantados cuáles eran esos Campos, cuando fueron creados, donde se localizaban y cuáles cultivos ensayaban; en un recorte temporal que se inicia en 1899, con creación del Servicio Agronómico, extendiéndose hasta 1914 cuando, por medidas de economía la SACOP es reorganizada y algunos Campos son desactivados.

PALABRAS CLAVE: Servicio Agronómico. Campos de Experiencia y Demostración. Informes de la Secretaría de Agricultura, Comercio y Obras Públicas del Estado de São Paulo. 


\section{INTRODUÇÃO}

O objeto de estudo do presente artigo são os Campos de Experiência e Demonstração criados ou encampados pelo governo do estado de São Paulo através da Secretaria da Agricultura, Comércio e Obras Públicas (SACOP). O arco temporal analisado tem início com a criação do Serviço Agronômico (1899), até o ano de 1914, quando, por medidas de economia, a SACOP é reorganizada e alguns Campos são suprimidos. O objetivo é resgatar a memória documental desses Campos de Experiência e Demonstração identificando a localização, a data de fundação e as culturas ensaiadas, tendo como fonte primária de pesquisa os Relatórios Anuais da Secretaria de Agricultura, Comércio e Obras Públicas ${ }^{1}$.

Os Campos de Experiência e Demonstração foram criados em função da necessidade de se aumentar e principalmente diversificar a produção agrícola paulista, o que, aos olhos do governo, só seria possível vulgarizando-se os processos modernos de agricultura. Como exposto no artigo da Revista Agrícola de 1898, intitulado "Os Campos de Experiência e Demonstração", essa vulgarização deveria ser massiva, chegando a todos os lavradores, mesmo que esses não entendessem a razão real do que lhes era recomendado. Nesse sentido, esses Campos funcionavam como verdadeiras escolas práticas, onde o ensino propagava-se por meio da demonstração, sob a ótica de que, "uma hora de observação pratica vale mais do que muitas explicações e leituras" (REVISTA AGRícOLA, 1898, p. 396-397).

Mais do que isso, esses Campos tinham por missão o estudo prático das culturas mais indicadas para cada região, por meio da identificação dos diferentes tipos de solo e de clima, além da indicação dos métodos e das máquinas mais adequadas para cada situação.

O que se pôde perceber por meio da análise dos Relatórios da SACOP é que os Campos de Experiência e Demonstração implantados em terras paulistas estavam divididos em quatro grupos: ligados às duas instituições já existentes e subordinadas a SACOP; vinculados aos "distritos agronômicos" especificados na criação do Serviço Agronômico e aqueles ligados aos novos cursos agronômicos.

O primeiro grupo identificado corresponde aos Campos de Experiência e Demonstração do Instituto Agronômico do Estado (IAE, atual Instituto Agronômico de Campinas - IAC). Em 1899, quando o Serviço Agronômico foi implantado por meio da Lei $n^{\circ} 678$, de 13 de setembro², já estava sob a pasta da Secretaria da Agricultura, a administração de duas importantes instituições do Estado: o Horto Botânico na capital e o IAE em Campinas. Como

\footnotetext{
${ }^{1}$ Este texto é parte integrante das pesquisas conduzidas por Laís Bim Romero em sua dissertação de Mestrado em andamento no Programa de Pós-graduação em Arquitetura e Urbanismo da FAAC/UNESPBauru, intitulada "Serviço de Distribuição de Mudas e Sementes. O fomento à arborização urbana no Estado de São Paulo no início do século XX" (título provisório), sob a orientação da Profa. Dra. Marta Enokibara.

2 Disponível em: <http://www.al.sp.gov.br/repositorio/legislacao/lei/1899/lei-678-13.09.1899.html>. Acesso em: 16 de agosto de 2017.
} 
previsto pela Lei, o Serviço Agronômico deveria absorver e reaproveitar esses estabelecimentos e seus órgãos anexos, tais como os Campos de Experiência do IAE, já existentes e distribuídos pelo território campineiro.

A mesma lei determinou que o território estadual fosse dividido em Distritos Agronômicos, cada qual com um administrador, intitulado Inspetor Agrícola, subordinado diretamente ao Secretário da Agricultura. Dissolvidos por esses Distritos, foram implantados alguns Campos, que constituem aqui um segundo grupo, chamado de: Campos de Experiência e Demonstração administrados pelos Inspetores de Agricultura. Dentro desse, foi possível identificar uma subgrupo, correspondente aos Campos de Experiência e Demonstração do "Ensino Agrícola Ambulante", que também eram administrados pelos Inspetores.

O terceiro grupo pode ser definido como os Campos de Experiência e Demonstração anexos as Escolas de Agricultura, estaduais e municipais. Essas Escolas, também previstas na lei de criação do Serviço Agronômico, formavam agrônomos diplomados em nível técnico ${ }^{3}$ e tinham como objetivo principal difundir o conhecimento agrícola por meio de trabalhos práticos; para isso, contavam com Campos anexos, onde eram realizadas as demonstrações e experiências. Soma-se a essas, as escolas privadas de ensino agrícola que, segundo o artigo $4^{\circ}$ da dita lei, poderiam receber a subvenção do Estado, desde que aprovados seus programas de ensino.

O quarto e ultimo grupo levantado no período, corresponde ao Horto Agrário Tropical de Cubatão, que apesar do nome diferenciado, havia sido criado com os mesmos propósitos dos demais Campos e era administrado pelo Horto Botânico de São Paulo ${ }^{4}$.

É importante ressaltar que esses foram os grupos que puderam ser levantados dentro do recorte temporal estudado, sendo notório que após esse período outros Campos foram criados, constituindo novos grupos, como é o caso dos Campos Temporários de Demonstração de Culturas, estabelecidos a partir de 1916, por meio do Decreto $n^{\circ} 2.681$ de 11 de julho ${ }^{5}$ que, como esclarece o próprio nome, tinham curta duração, em torno de uma ou duas safras do produto cultivado, sendo posteriormente levados para outras regiões.

Tomando por base os grupos apresentados, foram levantados ao todo 30 Campos, sendo: oito subordinados ao IAE, 13 administrados por Inspetores Agrícolas, nove pertencentes a escolas de agricultura e um dependente do Horto Botânico de São Paulo, conforme exposto na Tabela 1.

\footnotetext{
${ }^{3} \mathrm{O}$ curso de nível superior em agronomia era ministrado pela Escola Politécnica de São Paulo e segundo a Lei $n^{\circ} 678$, a criação das Escolas Práticas de Agricultura, não causaria prejuízo ao mesmo.

${ }^{4}$ Os Relatórios da SACOP do período não deixaram claro, se a área onde se localizava o Horto Botânico de São Paulo na Serra da Cantareira, era tida como um Campo de Experiência e Demonstração, por isso, optou-se não inseri-lo neste artigo. Para determinação precisa, se faz necessário realizar uma pesquisa complementar específica, apoiada em outras fontes, que não apenas os Relatórios Anuais da Secretaria. 5 Disponível em: <https://www.al.sp.gov.br/repositorio/legislacao/decreto/1916/decreto-268111.07.1916.html. Acesso em: 06 de agosto de 2018.
} 
Tabela 1: Relação de Campos de Experiência e Demonstração levantados nos Relatórios da SACOP (1988-1914).

\begin{tabular}{lll}
\hline 1 & $\begin{array}{l}\text { CAMPOS DE EXPERIÊNCIA E DEMONSTRAÇÃO DO INSTITUTO AGRONÔMICO DO ESTADO (IAE) } \\
\text { (NOME DO CAMPO) }\end{array}$ & (LOCALIZAÇÃO) \\
\hline Jardim de Guanabara & Campinas \\
Campo de Taquaral & Campinas \\
Campo de Santa Elisa & Campinas \\
Cafezal de Experiência e Demonstração de Monjolinho & Campinas \\
Campo Santa Amélia & Campinas \\
Campo Villa Marietta & Campinas \\
Campo Fazenda Santo Antônio & Campinas \\
Campo de Demonstração de Nova Odessa & Núcleo Colonial Nova \\
\hline
\end{tabular}

2 CAMPOS DE EXPERIÊNCIA E DEMONSTRAÇÃO ADMINISTRADOS PELOS INSPETORES DE AGRICULTURA (NOME DO CAMPO)

Campo de Experiência e Demonstração de Mogy das Cruzes

(LOCALIZAÇÃO)

Mogy das Cruzes

Campo de Experiência e Demonstração de Iguape*

Guaratinguetá

Campo de Experiência e Demonstração de Sorocaba

Iguape

Campo de Demonstração de Cultura de Arroz de Moreira Cezar

Sorocaba

Campo de Demonstração de Cultura de Trigo de Itapetininga

Pindamonhangaba

Itapetininga

2.1 CAMPOS DE EXPERIÊNCIA E DEMONSTRAÇÃO DO "ENSINO AGRÍCOLA AMBULANTE" ADMINISTRADOS PELOS INSPETORES DE AGRICULTURA

(NOME DO CAMPO)

Campo de Demonstração Fazenda Salto Grande

(LOCALIZAÇÃO)

Campo de Demonstração Fazenda do Sr. Pedro Hereman Limeira

Campo de Demonstração Fazenda Santo Antônio

Pereiras

Campo de Demonstração Fazenda do Dr. J. Soares Hungria Itapetininga

Campo de Demonstração Fazenda Aterradinho

Casa Branca

Campo de Demonstração Fazenda Acarassú

(não localizada)**

Campo de Demonstração Fazenda do Sr. Salvador Ignacio Pereira

Faxina

3 CAMPOS DE EXPERIÊNCIA E DEMONSTRAÇÃO ANEXOS AS ESCOLAS DE AGRICULTURA

\begin{tabular}{|c|c|c|}
\hline 3.1 & $\begin{array}{l}\text { ESCOLAS DE AGRICULTURA ESTADUAIS } \\
\text { (NOME DO CAMPO) }\end{array}$ & (LOCALIZACC̃̃O) \\
\hline & Escola Agrícola Prática de Piracicaba & Piracicaba \\
\hline & Aprendizado Agrícola "Dr. Bernardino de Campos"* & Iguape \\
\hline & Aprendizado Agrícola "João Tibiriçá" & São Sebastião \\
\hline \multirow[t]{5}{*}{3.2} & $\begin{array}{l}\text { ESCOLAS DE AGRICULTURA MUNICIPAIS } \\
\text { (NOME DO CAMPO) }\end{array}$ & (LOCALIZAÇÃO) \\
\hline & Escola Municipal de Agricultura de Batatais & Batatais \\
\hline & Escola Municipal de Trabalhadores Rurais "Senador Lacerda Franco" & Araras \\
\hline & Escola Prática “Dr. Carlos Botelho” & São Manoel \\
\hline & Escola Agrícola Prática "Dr. Candido Rodrigues" & Pindamonhangaba \\
\hline \multirow[t]{3}{*}{3.3} & $\begin{array}{l}\text { ESCOLAS DE AGRICULTURA PARTICULARES } \\
\text { (NOME DO CAMPO) }\end{array}$ & (LOCALIZAÇÃO) \\
\hline & Nome não citado & Lorena \\
\hline & Nome não citado & Campinas \\
\hline \multirow[t]{2}{*}{4} & $\begin{array}{l}\text { CAMPO DE EXPERIÊNCIA E DEMONSTRAÇÃO SUBORDINADO AO HO } \\
\text { (NOME DO CAMPO) }\end{array}$ & $\begin{array}{l}\text { UO PAULO } \\
\text { (LOCALIZAÇÃO) }\end{array}$ \\
\hline & Horto Agrário Tropical de Cubatão/ Ubatuba*** & Cubatão/ Ubatuba \\
\hline
\end{tabular}


pertencentes ao Campo. Assim, optou-se por inserir esse Campo nas duas categorias, tendo em vista que antes de ser vinculado a um estabelecimento de ensino agrícola, era um Campo independente, administrado pela inspetoria de agricultura.

** Não foi possível identificar a localização da Fazenda Acarassú nas informações contidas nos Relatórios da SACOP.

*** O Horto Agrário Tropical funcionou na cidade de Cubatão desde sua criação em 1905 até 1912, quando foi transferido para Ubatuba, passando a se chamar Horto Tropical de Ubatuba.

Fonte: Elaborado pelas autoras (2018) com base das informações contidas nos Relatórios da SACOP (1988-1914).

Nota-se que havia uma variação na nomenclatura desses estabelecimentos - Campo; Campo de Experiência e Demonstração; Campo de Demonstração- o que, por sua vez, não alterava sua função principal de experimentar e propagar conhecimentos agrícolas.

Assim, com base nos Relatórios Anuais da Secretaria da Agricultura, pretende-se resgatar informações importantes sobre os 30 Campos apresentados, tais como: o ano de sua criação, o período em que foi utilizado, sua localização e as culturas a que se dedicavam; chegando a dados que demonstrem a amplitude dessa estrutura criada pelo governo no território paulista.

\section{CAMPOS DE EXPERIÊNCIA E DEMONSTRAÇÃO DO INSTITUTO AGRONÔMICO DO ESTADO (IAE)}

A Imperial Estação Agronômica (posteriormente Instituto Agronômico do Estado e atual Instituto Agronômico de Campinas) foi fundada em 1887. Além das edificações dos setores administrativos, laboratórios e biblioteca, havia uma área aberta onde eram acomodadas as espécie agrícolas, silvícolas e ornamentais em estudo, conhecida como Jardim de Guanabara. Em 1894, em função do numero de visitas que recebia de fazendeiros e lavradores da região, 0 Jardim tornou-se um Campo de Experiência e Demonstração (RELATÓRIO do IAE, 1894, p. 22) e passou a abrigar as principais pesquisas de estrumação, adubação, poda, enxerto e multiplicação, relativas a todas as culturas do Instituto. O Campo, que já contavam com uma seção de aclimatação de espécies arbóreas desde 1890 (RELATÓRIO IAE, 1893, p. 171), empenhou-se na reprodução e distribuição de espécies, tendo em vista a arborização de ruas e o embelezamento de jardins, o que acabou sendo limitado por seu espaço restrito.

Problema semelhante via-se em Taquaral, o primeiro Campo fora da sede do Instituto, adquirido durante a administração transitória de Uchôa Cavalcanti, entre abril de 1890 e março de 1891 (RELATÓRIO IAE, 1892, p.17) e que, além das limitações territoriais, sofria com a escassez de água e a presença massiva de formigas. Apenas após o controle dessa praga o Campo tornou-se verdadeiramente útil, dedicando-se ao cultivo do café. O eucalipto foi a primeira espécie com fins "não agrícolas" cultivada nesse Campo, tendo sido o seu primeiro plantio realizado em 1896, como forma de experiência para se combater a febre amarela (RELATÓRIO SACOP, 1896, p. 74). Em 1899, as espécies do Campo foram ampliadas e algumas frutíferas foram introduzidas (Relatório SACOP, 1899, p. 17).

O Campo de Santa Elisa foi o próximo a ser adquirido, no ano de 1898, porém sua utilização era anterior, como demonstra o Relatório do IAE relativo aos trabalhos do ano de 1892. Nesse 
relatório, o diretor do IAE informa que estavam sendo utilizadas as terras da Fazenda Santa Elisa, que haviam sido cedidas por seu proprietário, o Barão Geraldo Rezende (1846-1907) ${ }^{6}$, para realização de estudos econômico sobre os custos relativos ao plantio de culturas.

Mesmo sendo o Campo mais extenso sob a posse do Instituto, no ano de 1907, tendo em vista a implantação do Campo de Experiência e Demonstração de Nova Odessa (criado em 1905), seus trabalhos foram abandonados e suas coleções transferidas. No ano seguinte, em 1908, Nova Odessa foi desanexada do IAE. Assim, o Campo de Santa Elisa foi reativado e melhorado, no intuito de se transformar em uma "fazenda de aplicações e demonstrações em grande escala, servindo de exemplo de administração [...] de uma fazenda agrícola" (RELATÓRIO SACOP, 1909, p. 34). Para isso e buscando abranger todos os segmentos agrícolas, em 1909 foi iniciado um pequeno viveiro de espécies frutíferas, arbóreas e silvícolas, em uma área da mata nativa existente na Fazenda.

Segundo os Relatórios da SACOP dos anos subsequentes, os objetivos propostos ao Campo de Santa Elisa se cumpriram, de forma que a fazenda tornou-se uma grande referência de organização, qualidade e modernidade.

Essas características também foram absorvidas pelo cafezal de Monjolinho, outro Campo de Experiência e Demonstração do IAE, situado no entorno de Santa Elisa, também em terras pertencentes ao Barão Geraldo Rezende. O inicio de sua utilização pelo IAE data de 1892, porém sua compra só se concretizou em 1912, com o intuito de tornar permanentes as demonstrações práticas de cafeicultura ali realizadas (RELATÓRIO SACOP, 1912-1913, p. 50).

Nota-se ainda que, o IAE contou com terras de outras duas fazendas pertencentes ao Barão Geraldo Resende, que vieram a constituir Campos temporários do Instituto: o Campo de Santa Amélia e o Campo Villa Marietta. Esses Campos foram colocados à disposição da instituição no ano de 1893, tendo como função principal a realização de experiências de estrumação de café, de forma a copara-las com as realizadas nos demais Campos. A partir de 1898, os dois Campos deixam de aparecer nos Relatórios da SACOP, assim, ao que tudo indica, quando o Serviço Agronômico foi implantado, esses Campos já não eram utilizados. O mesmo pode ser verificado com relação ao Campo da Fazenda Santo Antônio, que aparece exclusivamente no Relatório da SACOP do ano de 1896, onde é informado que suas terras haviam sido cedidas por seu proprietário ${ }^{7}$ para realização de experiências de estrumação de cafeeiros.

No ano de 1905 foi fundado o ultimo Campo vinculado ao Instituto Agronômico, o Campo do Núcleo Colonial Nova Odessa, que diferente dos demais, não se localizava em terras

\footnotetext{
${ }^{6}$ O Barão Geraldo Ribeiro de Souza Rezende (1846-1907) mudou-se para Campinas em 1870 para assumir a administração da Fazenda Santa Genebra, que recebera como herança de sua avó materna. Graças ao seu talento na lavoura, Santa Genebra tornou-se uma das maiores fazendas de café do Estado de São Paulo. Seu interesse pelo cultivo da terra o tornou, ainda, um dos maiores e mais ativos benfeitores do Instituto Agronômico do Estado no período. Fato interessante é que, os nomes das fazendas cedidas pelo Barão para serem utilizadas como Campos de Experiência do IAE, homenageavam suas três filhas: Amélia, Elisa e Marietta.

${ }^{7}$ Não foi possível identificar o nome do proprietário da Fazenda Santo Antônio referida.
} 
campineiras, mas sim no núcleo colonial de mesmo nome. Sua utilização estendeu-se até 1908, focando no cultivo de espécies agrícolas e arbóreas, na realização de experiências úteis ao IAE e na orientação aos colonos ali residentes.

\section{CAMPOS DE EXPERIÊNCIA E DEMONSTRAÇÃO ADMINISTRADOS PELOS INSPETORES DE AGRICULTURA}

Esses Campos resultaram da necessidade de se estudar o clima e o solo das diferentes regiões do Estado, tendo em vista que até então as pesquisas eram concentradas na cidade de Campinas, nos Campos do IAE.

A divisão do Estado em Distritos Agronômico foi à primeira iniciativa do governo para solucionar tal demanda. Assim, por meio do Decreto $n^{\circ} 752$ de 15 de março de $1900^{8}$, o Estado foi dividido em seis distritos, tendo como cidades sedes, respectivamente: a capital São Paulo, Campinas, Ribeirão Preto, São Carlos do Pinhal e Sorocaba. Inicialmente, a intenção governamental era de se instalar um Campo de Experiência e Demonstração em cada uma dessas cidades sob a administração direta do Inspetor de Agricultura local, o que não se concretizou pela escassez de verba e pela dificuldade de se conseguir os terrenos necessários nas áreas das sedes.

Segundo o Relatório da SACOP de 1901, naquele ano só foi possível à instalação de Campos em três Distritos Agronômicos, ainda assim, graças à concessão de terras realizadas pelas Câmaras Municipais locais. Com isso, foram instalados os Campos de Experiência e Demonstração nas cidades de Mogy das Cruzes e Guarantiguetá ( $1^{\circ}$ Distrito Agronômico), em terras do Núcleo Colonial Campos Salles ( $2^{\circ}$ Distrito) e em Iguape ( $6^{\circ}$ Distrito).

Aparentemente, desses quatro Campos, o que mais se desenvolveu nos primeiros anos foi o de Iguape. Segundo o Relatório da SACOP de 1902 (p. 20), sua área toda estava ocupada com pesquisas, especialmente as relacionadas ao cultivo do arroz, que era bastante indicado para a zona, e do cacau, considerado promissor. Ainda em 1902, o Campo passou a contar com o Aprendizado Agrícola "Dr. Bernardino de Campos", que por se tratar de uma instituição de ensino, será abordado mais adiante em tópico específico. (RELATÓRIO SACOP, 1904, p. 10).

Também em 1902, foi instalado o primeiro Campo localizado em uma cidade sede, o Campo de Experiências de Sorocaba no $5^{\circ}$ Distrito, situado em terras doadas pela municipalidade ao governo do Estado. O Campo tinha como cultura principal o algodão, porém dedicava-se também ao cultivo de essências florestais, que haviam sido doadas pelo Horto Botânico de São Paulo (RELATÓRIO SACOP, 1903, p. 22), e aos estudos sobre a "galinha da terra" e as formas de melhorar sua carne e aumentar sua produção de ovos (RELATÓRIO SACOP, 1904, p. 42).

8 Disponível em: https://www.al.sp.gov.br/repositorio/legislacao/decreto/1900/decreto-75215.03.1900.ht. Acesso em: 05 de junho de 2018. 
Nos anos seguintes, os Distritos Agronômicos passaram por duas reorganizações, em 1904 e 1907. A primeira, promulgada pelo Decreto $n^{\circ} 1188$ de 19 de janeiro de $1904^{9}$, foi necessária devido à falta de recursos financeiros na Secretaria, o que levou ao corte de três, dos seis inspetores agrícolas contratados. Consequentemente o número de Distritos Agronômicos também foi reduzido, ficando as cidades de São Paulo, Araras e Sorocaba, respectivamente as sedes do $1^{\circ}, 2^{\circ}$ e $3^{\circ}$ Distritos. A segunda aconteceu em 1907, quando a SACOP passou por uma grande e expressiva reforma (Reforma Carlos Botelho) promulgada pelo Decreto $n^{\circ} 1459$ de 10 de abril de $1907^{10}$. O Estado foi novamente dividido, formando-se cinco Distritos agrupados conforme as linhas férreas que os serviam ${ }^{11}$; o número de inspetores foi equiparado e os serviços, avolumados pela redução de 1904, voltaram à regularidade.

Em meio a essas reorganizações, foi fundado em 1906, o Campo de Demonstração de cultura de arroz de Moreira Cezar (Decreto $n^{\circ} 1412$ de 17 de outubro de $1906^{12}$ ), no município de Pindamonhangaba. Segundo o Relatório da SACOP de 1907 (p. XIII), em pouco tempo de funcionamento esse Campo já demonstrava resultados bastante significativos, uma vez que vários lavradores paulista e também outros de fora do Estado, vinham adotando, com vantagem, os processos de cultivo ali praticados. No final de 1908, os trabalhos no Campo cessaram, visto já terem produzidos os resultados desejados, "podendo-se considerar como divulgados entre os lavradores do Estado os processos de cultura de arroz por irrigação" (RELATÓRIO SACOP, 1909, p. XXI).

Assim, buscando aproveitar o material e a mão de obra excedentes do Campo de Moreira Cezar, o governo criou, em terrenos concedidos pela municipalidade, a Comissão de Demonstração de cultura do trigo de Itapetininga, no ano de 1909.

9 Disponível em: <https://www.al.sp.gov.br/repositorio/legislacao/decreto/1904/decreto-118819.01.1904.html>. Acesso em: 26 de julho de 2018.

${ }_{10}$ Disponível em: <https://www.al.sp.gov.br/repositorio/legislacao/decreto/1907/decreto-145910.04.1907.html>. Acesso em: 26 de julho de 2018.

${ }^{11} \mathrm{O} 1^{\circ}$ Distrito compreendia os municípios servidos pela Estrada de Ferro Central do Brasil, pela São Paulo Railway até Alto da Serra, pela Sorocabana até São João, pela Ituana até Itupeva, pela Paulista até Limeira e finalmente pelas linhas Bragantina e Itatibense. Os municípios do $2^{\circ}$ Distrito eram os servidos por todas as linhas da Mogiana, a bitola larga da Paulista de Limeira e Cordeiro, e desse até Porto Ferreira, com o ramal da Descalvadense. $03^{\circ}$ Distrito abrangia Rio Claro, todas as linhas de bitola estreita da Paulista e da Ituana a partir de Salto e Itupeva. $\mathrm{O} 4^{\circ}$ Distrito era composto por Itu e todos os municípios servidos pela Sorocabana, já o $5^{\circ}$ Distrito, pelos municípios do litoral e os da Bacia do Rio Ribeira (RELATÓRIO SACOP, 1901, p. 5).

12 Disponível em: <https://www.al.sp.gov.br/repositorio/legislacao/decreto/1906/decreto-141217.10.1906.html. Acesso em: 26 de julho de 2018. 


\subsection{CAMPOS DE EXPERIÊNCIA E DEMONSTRAÇÃO DO "ENSINO AGRÍCOLA AMBULANTE" ADMINISTRADOS PELOS INSPETORES DE AGRICULTURA}

O sucesso alcançado com os Campos localizados em Pindamonhangaba e Itapetinga contribuiu para que, em 1911, fosse regulamentado o "Ensino Agrícola Ambulante"13, por meio do Decreto $n^{\circ} 1992-A$ de 31 de janeiro ${ }^{14}$. Esse tipo de ensino itinerante também se empenhava em ministrar a educação prática aos lavradores, porém valia-se de Campos instalados provisoriamente em propriedades particulares, sendo que os primeiros registrados pela SACOP situavam-se em Villa Americana, Ipanema e Chave Americana ${ }^{15}$ (RELATÓRIO SACOP, 19101911, p. 33). Por estarem subordinados à administração dos Inspetores Agrícolas, esses Campos podem ser considerados como uma subclasse dos "Campos de Experiência e Demonstração administrados pelos Inspetores de Agricultura". Segundo os Relatórios da SACOP dos anos de 1912 e 1913, foram implantados sete Campos nesses moldes (Tabela 2), que tinham por fim propagar os melhores processos aplicáveis à lavoura do algodão (RELATÓRIO SACOP, 1912-1913, p. 41-42).

Tabela 2: Campos de Experiência e Demonstração do "Ensino Agrícola Ambulante".

\begin{tabular}{|c|c|c|c|}
\hline Fazenda/ Proprietário & Município & Localização & Linha Férrea \\
\hline $\begin{array}{l}\text { Fazenda Salto Grande da Rawlinson, } \\
\text { Müller \& Comp. }\end{array}$ & Campinas & Villa Americana & Paulista \\
\hline Fazenda do Sr. Pedro Hereman & Limeira & $\begin{array}{l}\text { À 0,5km da Estação de Guaiquica, } \\
\text { entre o Núcleo Colonial Campos } \\
\text { Salles e os três núcleos de Conchal }\end{array}$ & Fluminense \\
\hline $\begin{array}{l}\text { Fazenda Santo Antônio do Sr. Manoel } \\
\text { Leite de Magalhães }\end{array}$ & Pereiras & À $3 \mathrm{~km}$ de Pereiras e a $6 \mathrm{~km}$ de Tatuí & \multirow{5}{*}{ Sorocabana } \\
\hline Fazenda do Dr. J. Soares Hungria & Itapetininga & $\begin{array}{l}\text { Na Estação Morro Alto, entre Tatuí e } \\
\text { Itapetininga }\end{array}$ & \\
\hline $\begin{array}{l}\text { Fazenda Atterradinho da Companhia } \\
\text { Agrícola, Industrial e Pastoril }\end{array}$ & Casa Branca & $\begin{array}{l}\text { À “4 léguas" das Estação de } \\
\text { Engenheiro Hermillo }\end{array}$ & \\
\hline $\begin{array}{c}\text { Fazenda Aracassú do Sr. Carlos } \\
\text { Howard }\end{array}$ & $\begin{array}{c}\text { (não } \\
\text { informado) }\end{array}$ & (não informado) & \\
\hline $\begin{array}{l}\text { Fazenda do Sr. Salvador Ignacio } \\
\text { Pereira }\end{array}$ & Faxina & Na Estação Engenheiro Bacellar & \\
\hline
\end{tabular}

Fonte: Elaborado pelas autoras (2018) com base das informações contidas no Relatório da SACOP, 1912-1913, p. 41 e 42 .

${ }^{13}$ Vale lembrar que, a criação do "Ensino Agrícola Ambulante" foi importante também para a organização de "Cooperativas Agrícolas" dissolvidas pelo Estado, mas isso é outro assunto, que devido à complexidade deve ser tratado separadamente.

14 Este Decreto também foi responsável por uma reorganização na SACOP. Disponível em: <https://www.al.sp.gov.br/repositorio/legislacao/lei/1911/lei-1310A-30.12.1911.html>. Acesso em: 01 de Agosto de 2018.

${ }^{15}$ Por não terem sido encontradas maiores informações referentes aos Campos instalados em Ipanema e Chave Americana nos anos subsequentes dos Relatórios da SACOP, entende-se que os cultivos ali não se estenderam para além de 1911. 


\section{CAMPOS DE EXPERIÊNCIA E DEMONSTRAÇÃO ANEXOS AS ESCOLAS DE AGRICULTURA}

Com o nome de "fazenda-modelo", a Lei n 678 previa que cada escola de ensino profissional agrícola criada tivesse em terras um Campo de Experiência e Demonstração. Como exposto por Faria (1992, apud VERSIEUX; GONÇALVES, 2013), no período havia uma indistinção entre os termos - Campos de Experiência e Demonstração e Fazendas-Modelo- sendo que ambos eram definidos como "instituições de ensino agrícola prático"; voltados para a demonstração prática de técnicas e processos.

No recorte temporal desta pesquisa, verificou-se a existências de três Escolas Agrícolas estaduais, localizadas em Piracicaba, Iguape e São Sebastião; quatro municipais, subvencionadas pelo Estado, nas cidades de Batatais, Araras, São Manoel e Pindamonhangaba; e duas particulares, pertencentes a ordens religiosas, em Lorena e Campinas.

\subsection{CAMPOS DE EXPERIÊNCIA E DEMONSTRAÇÃO ANEXOS AS ESCOLAS DE AGRICULTURA ESTADUAIS}

A primeira Escola Pratica de Agricultura paulista foi criada na Fazenda São João da Montanha em Piracicaba, por meio da Lei $n^{\circ} 587$ de 31 de agosto de $1898^{16}$, que previa uma "escola prática de agricultura, com um campo de experiências e um posto zootécnico" (RELATÓRIO SACOP, 1900, p.17); porém sua instalação foi concluída apenas em 1899, em execução do artigo 13 da Lei ${ }^{\circ} 678$ de criação do Serviço Agronômico. Em 1901, a instituição, até então conhecida como "Escola Agrícola Prática de Piracicaba", foi renomeada como "Escola Agrícola Luiz de Queiroz"17, em justa homenagem a Luiz Vicente de Sousa Queiroz que, em 1892, havia doado suas terras ao governo estadual (RELATÓRIO SACOP, 1900, p.17).

A Fazenda-modelo anexa a Escola, onde se localizavam os Campos de Experiência e Demonstração, funcionou sob a direção direta da SACOP durante o ano de 1903 (Decreto $\mathrm{n}^{\circ}$ 1076 de 22 de Dezembro de $1902^{18}$ ), sem prejuízo, contudo, ao ensino prático dos alunos (RELATÓRIO SACOP, 1903, p. 06). No ano seguinte a administração retornou a Diretoria da Escola, o que intensificou seus trabalhos e sua organização (RELATÓRIO SACOP, 1904, p. 06), sendo que em 1905, a fazenda possuía representantes de todas as principais culturas agrícola, frutíferas e ornamentais em estudo no país (RELATÓRIO SACOP, 1905, p. 05).

\footnotetext{
${ }^{16}$ Disponível em: < https://www.al.sp.gov.br/repositorio/legislacao/lei/1898/lei-587-31.08.1898.html>. Acesso em: 19 de outubro de 2018.

${ }^{17}$ Em 1917, esta instituição passa a se chamar Escola Agrícola Luiz de Queiroz. Em 1931, Escola Superior de Agricultura Luiz de Queiroz e em 1934, Escola Superior de Agricultura Luiz de Queiroz (ESALQ) da Universidade de São Paulo (USP), tornando-se subordinada a USP.

18 Disponível em: < https://www.al.sp.gov.br/repositorio/legislacao/decreto/1902/decreto-107622.12.1902.html>. Acesso em: 19 de outubro de 2018.
} 
Em 1902, o Inspetor Agrícola Lourenço Granato, recebeu a autorização da SACOP para "construir, junto ao campo de experiências [e demonstração de Iguape], um barracão de madeira, [...], no qual pudesse dar aulas" (RELATÓRIO SACOP, 1904, p. 10) tendo em vista o interesse que observava entre as crianças da região. Com isso, o Campo de Experiência e Demonstração de Iguape existente desde 1901, passou a compor o Aprendizado Agrícola “Dr. Bernardino de Campos".

Tendo em vista os bons resultados alcançados com a instituição de Iguape, o governo criou em 1905, o Aprendizado Agrícola "João Tibiriça” na cidade de São Sebastião (RELATÓRIO SACOP, 1905, p. 3). Conforme demonstra o Relatório da SACOP do ano de 1905, "em ambos esses aprendizados, o ensino pratico de agricultura [era] feito nos campos de experiência anexos ${ }^{19}$, nos quaes cada alunno [tinha] a seu cargo um lote para cultivar [...]" (RELATÓRIO SACOP, 1905, p. 03). Em 1914, esses Campos fora suprimidos, tendo em vista a reforma da Secretaria da Agricultura e as medidas de economia que o governo foi obrigado a adotar.

\subsection{CAMPOS DE EXPERIÊNCIA E DEMONSTRAÇÃO ANEXOS AS ESCOLAS DE AGRICULTURA MUNICIPAIS}

Pertencem a esse grupo os Campos de Experiência e Demonstração anexos as Escolas de Agricultura criadas por iniciativa municipal que recebiam ajuda do Estado, por meio do fornecimento de máquinas, equipamentos e com o auxilio dos inspetores de agricultura.

No recorte temporal da pesquisa, foram identificadas quatro escolas com essas características, cada qual com seu Campo de Experiência e Demonstração anexo, sendo elas: a Escola Municipal de Agricultura de Batatais, fundada em 1901 (RELATÓRIO SACOP, 1910, p. 10); a Escola Municipal de Trabalhadores Rurais "Senador Lacerda Franco" na cidade de Araras, fundada em 1902 (RELATÓRIO SACOP, 1902, p. 18); a Escola Prática “Dr. Carlos Botelho” em São Manoel e a Escola Agrícola Prática "Dr. Candido Rodrigues" em Pindamonhangaba, sendo que as duas ultimas foram fundadas no ano de 1909 (RELATÓRIO SACOP, 1909, p. 5-6).

\subsection{CAMPOS DE EXPERIÊNCIA E DEMONSTRAÇÃO ANEXOS AS ESCOLAS DE AGRICULTURA PARTICULARES}

Nos Relatórios da SACOP do período estudado, foi localizada apenas uma citação sobre esse tipo de instituição, no exemplar relativo aos anos de 1912-1913, onde é informado que "além da Escola Agrícola Municipal de Araras, custeada com subvenção do Estado, funcionam idênticos institutos em Lorena e em Campinas, fundados e mantidos por ordens religiosas" (RELATÓRIO SACOP, 1912-1913, p. XXXIV, grifo nosso). No Relatório consta ainda que, "bem

\footnotetext{
${ }^{19}$ Administrativamente, os dois Aprendizados pertenciam ao Estado, sendo subordinados ao inspetor de agricultura local - Lourenço Granato - porém, tendo em vista seu vinculo com as instituições de ensino, optou-se por agrupa-los nessa categoria.
} 
compreendendo a cooperação valiosa que á aç̧ão oficial podem prestar os institutos de ensino agrícola, mantidos pela iniciativa privada, para eles temos volvido a nossa atenção procurando amparar tão louvável esforço" (RELATÓRIO SACOP, 1912-1913, p. XXXIV).

\section{CAMPO DE EXPERIÊNCIA E DEMONSTRAÇÃO SUBORDINADO AO HORTO BOTÂNICO DE SÃO PAULO}

Nesse grupo está inserido o Horto Agrário Tropical de Cubatão que, segundo o Relatório da SACOP de 1905 (p. 33), fora criado para suprir a necessidade de se estudar as questões agrárias relativas ao cultivo de plantas tropicais, improprias para áreas de planalto, porém que bem se desenvolveriam na região litorânea do Estado. Assim, em meados de 1905, o Horto foi instalado aos moldes de um Campo de Experiência e Demonstração e subordinado ao Horto Botânico de São Paulo. Suas principais culturas eram o cacau, o coqueiro, a seringueira, o arroz, e algumas espécies frutíferas como a bananeira, a amoreira e a laranja. Em 1912, o estabelecimento foi transferido para Ubatuba, em uma área pertencente ao extinto Núcleo Colonial "Conde de Pinhal", passando a ser denominado como Horto Tropical de Ubatuba. A transferência ocorreu porque o governo acreditava que nessa localidade as condições para o cultivo de espécies tropicais eram mais favoráveis (RELATÓRIO SACOP, 1910-1911, p. 49).

\section{A REDE DE CAMPOS DE EXPERIÊNCIA E DEMONSTRAÇÃO}

Tendo em vista o exposto, todas as localidades - cidades e núcleo colonial - que apresentavam em suas terras um Campo de Experiência e Demonstração foram demarcadas no mapa estadual do período (Mapa 1).

Verificou-se que, com exceção dos Campos das cidades litorâneas de São Sebastião e Ubatuba, todos os outros foram posicionados em localidades servidas por ferrovias. Pelo que se pôde levantar, a intensão governamental era de instala-los o mais próximo possível dos trilhos, colocando-os sempre a vista de quem por ali passasse. Como exemplo, temos o trecho do Relatório da SACOP de 1907, que faz referência ao Campo instalado em Nova Odessa.

O [Campo de Experiência e Demonstração] de Nova Odessa, dependente do Instituto Agronômico, criado junto ao Nucleo Colonial daquela denominação, [instalado] á margem da estrada de ferro Paulista, á vista dos inúmeros passageiros que por ali transitam diariamente, como que convidando-os a irem receber os ensinamentos dos novos processos agrícolas [...] (RELATÓRIO SACOP, 1907, p. XIII). 


\section{Revista Nacional de}

Mapa 1: Demarcação das cidades e núcleo colonial que apresentavam Campos de Experiência e Demonstração em suas terras entre os anos de 1899 e 1914 e linhas ferroviárias.

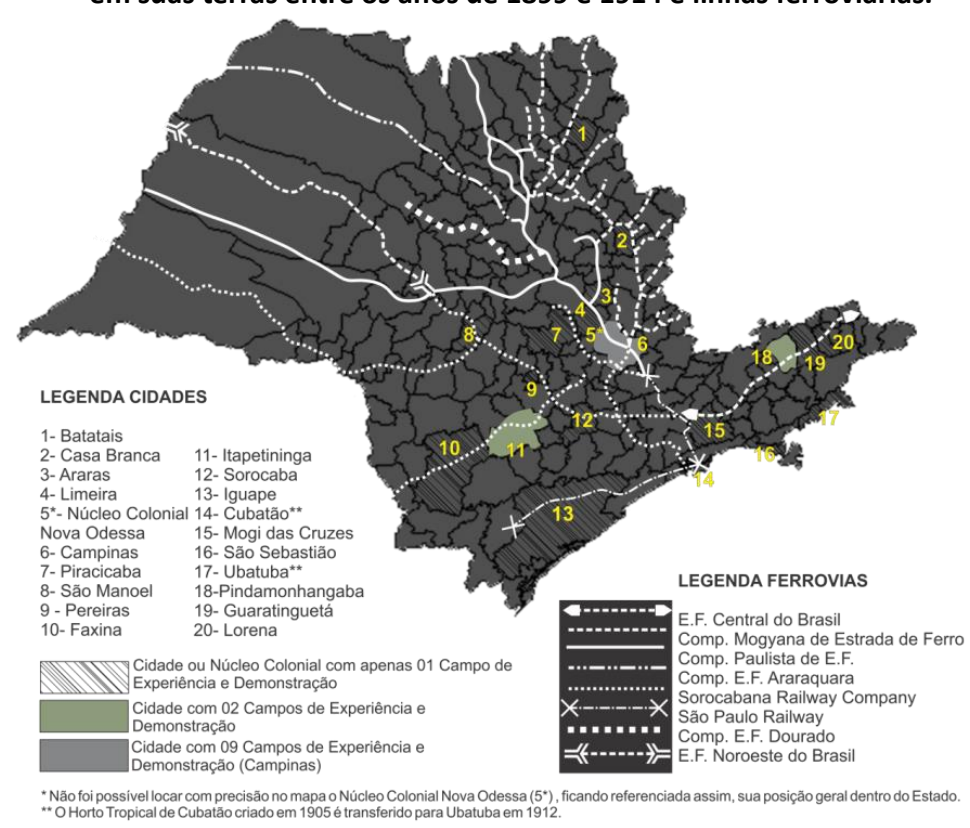

Fonte: Mapa base do ano de 1920, disponível em: <

http://produtos.seade.gov.br/produtos/500anos/index.php?tip=mapa>. Acesso em 19 de outubro de 2018.

Informações e intervenções elaboradas pelas autoras (2018).

Observa-se através do Mapa 1, que a localização dos Campos e sua articulação privilegiada com as ferrovias atribuíram-lhes um caráter de rede, por onde circulavam informações, produtos e pessoas. Como exposto por Versiex e Gonçalves (2013), essa característica vinha de uma determinação do governo federal e era repetida em diferentes estados, como por exemplo, em Minas Gerais.

Nota-se que cinco companhias ferroviárias serviam os Campos levantados nesse estudo. Dessas, a Sorocabana era a que chegava ao maior numero de localidades - Campinas, Sorocaba, Pereiras, Itapetininga, Faxina, Piracicaba e São Manuel; enquanto a Mogiana atendia ao menor número - apenas os Campos localizados em Batatais e Casa Branca. A Paulista chegava à três cidades (Limeira, Araras e Campinas) e ao Núcleo Colonial de Nova Odessa; já a São Paulo Railway e a E.F. Central do Brasil abordavam três localidades cada, a primeira: Mogi das Cruzes, Iguape, Cubatão, e a segunda: Guaratinguetá, Pindamonhangaba, Lorena.

É importante ressaltar que, o Horto Agrário Tropical era servido por linha ferroviária (São Paulo Railway) enquanto localizava-se em Cubatão; ao ser transferido para Ubatuba essa ligação foi perdida, o que, porém, foi compensado pela melhoria nas condições de cultivo de espécies tropicais, finalidade para a qual havia sido criado, conforme citado anteriormente.

Outro fato relevante é que o Campo localizado em Iguape (inicialmente Campo de Experiência de Demonstração de Iguape e depois Campo anexo ao Aprendizado Agrícola "Dr. Bernardino de Campos") não chegou a ser servido pela ferrovia, tendo em vista que, o ramal Santos-Juquiá 


\section{Revista Nacional de}

da E.F. São Paulo Railway só chegou à localidade no ano de 1915, ou seja, um ano após ter sido desativado o Aprendizado Agrícola "Dr. Bernardino de Campos" e seu Campo anexo.

O grande destaque recai sobre a cidade de Campinas, que além de apresentar o maior número de Campos de Experiência e Demonstração em suas terras (nove no total) ${ }^{20}$, possuía a maior quantidade de linhas férreas os servindo, sendo: a Paulista, a Sorocabana, a Mogiana, a Fluminense e o Ramal Férreo Campineiro ${ }^{21}$.

Como nos esclarece o Mapa 2 abaixo, nos Campos posicionados em Campinas sob a responsabilidade do IAE observa-se que: nas proximidades do Jardim de Guanabara passavam os trilhos do Ramal Férreo Campineiro (que tinha início na plataforma da Cia Paulista e chegava até o bairro Arraial do Souzas) e da E.F. Mogiana, sendo que a Estação Guanabara dessa Companhia posicionava-se paralelamente ao Campo. Os trilhos da Mogiana ainda se aproximavam das terras do Campo do Taquaral, enquanto os Campos de Santa Elisa e Monjolinho eram cortados pelos trilhos da E. F. Fluminense. Já o Campo de Villa Marietta, quando em funcionamento, localizava-se próximo aos trilhos da Paulista.

\footnotetext{
${ }^{20}$ Conforme demonstra o Mapa 1, Campinas apresentava o maior número de Campos em suas terras (nove Campos), seguida por Pindamonhangaba e Itapetininga, com dois Campos cada. As demais localidades apresentadas no artigo possuíam apenas um Campo de Experiência e Demonstração em suas terras.

${ }^{21}$ A Companhia Ramal Férreo Campineiro foi inaugurada em 1889 e abriu seus serviços ao público no ano seguinte em um trecho que tinha início na plataforma da Cia Paulista e chegava até o bairro Arraial do Souzas. Em 1912, a empresa foi comprada pela Cia. Campineira de Tração, Luz e Força, a qual pertenceu até 1950. Entre 1950 e 1952 ficou sob a posse da Companhia Paulista de Força e Luz (CFPL) e posteriormente foi entregue a E.F. Sorocabana.
} 
Revista Nacional de

Gerenciamento de Cidades

National Journal of Cities Management

Mapa 2: Planta da cidade de Campinas do ano de 1929 com a locação dos Campos de Experiência e Demonstração do IAE e as linhas férreas que os serviam.

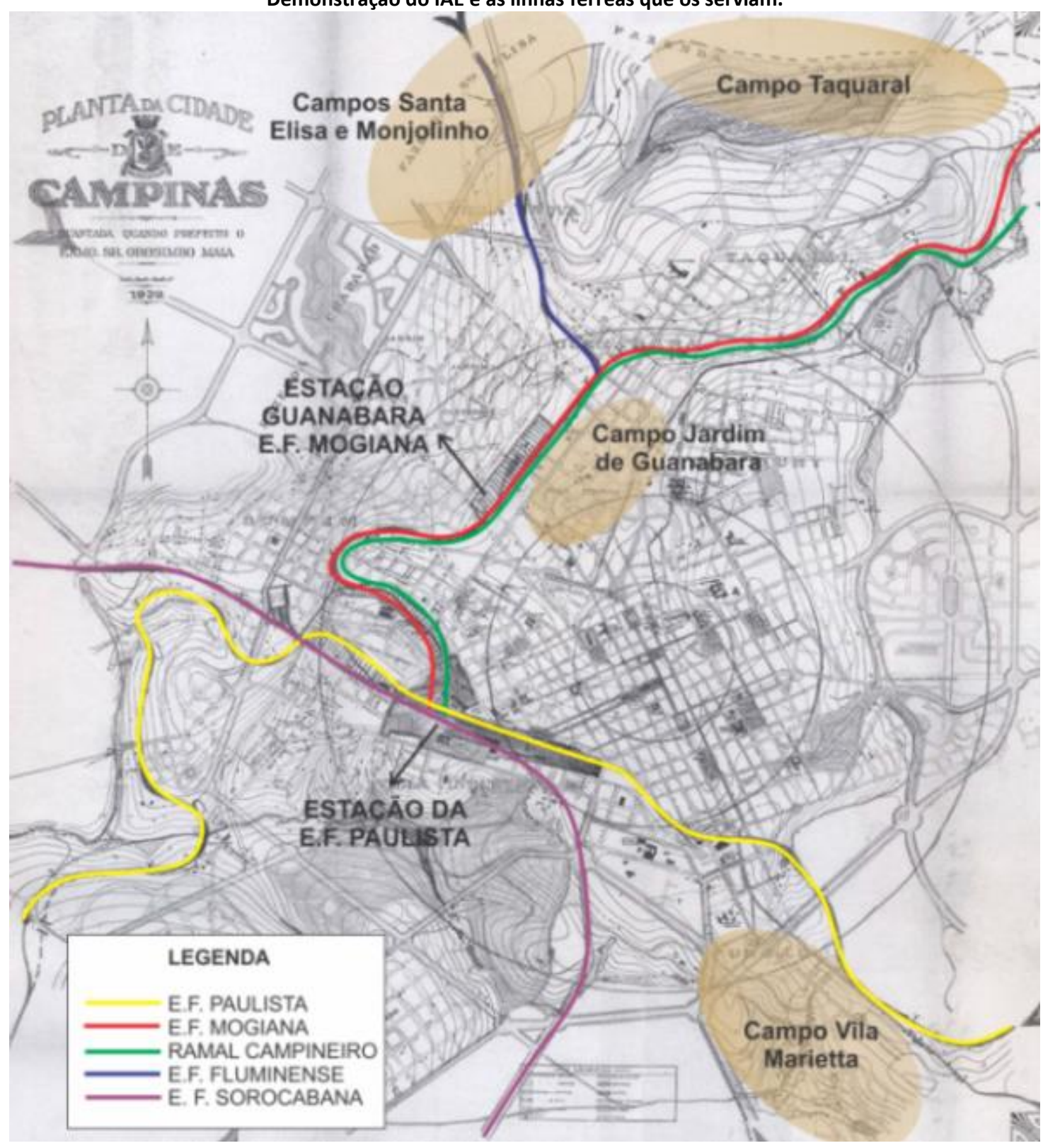

Fonte: Mapa base disponível em: <

http://www.campinas.sp.gov.br/governo/seplama/luos/p3a/anexo3_fichas_paisagensculturais/anexo_3.pdf>. Acesso em 24 de outubro de 2018. Informações e intervenções elaboradas pelas autoras (2108).

Por fim, os Campos mais afastados do núcleo urbano de Campinas, localizados nas Fazendas Santo Antônio e Salto Grande, eram próximos, respectivamente, das linhas da E.F. Sorocabana e do Ramal Campineiro, conforme demonstra a Imagem 1. 


\section{Revista Nacional de}

Imagem 1: Detalhe do mapa município de Campinas, destacando a posição das Fazendas Santo Antônio e Salto Grande, que abrigaram Campos de Experiência e Demonstração e as linhas férreas que por ali passavam.

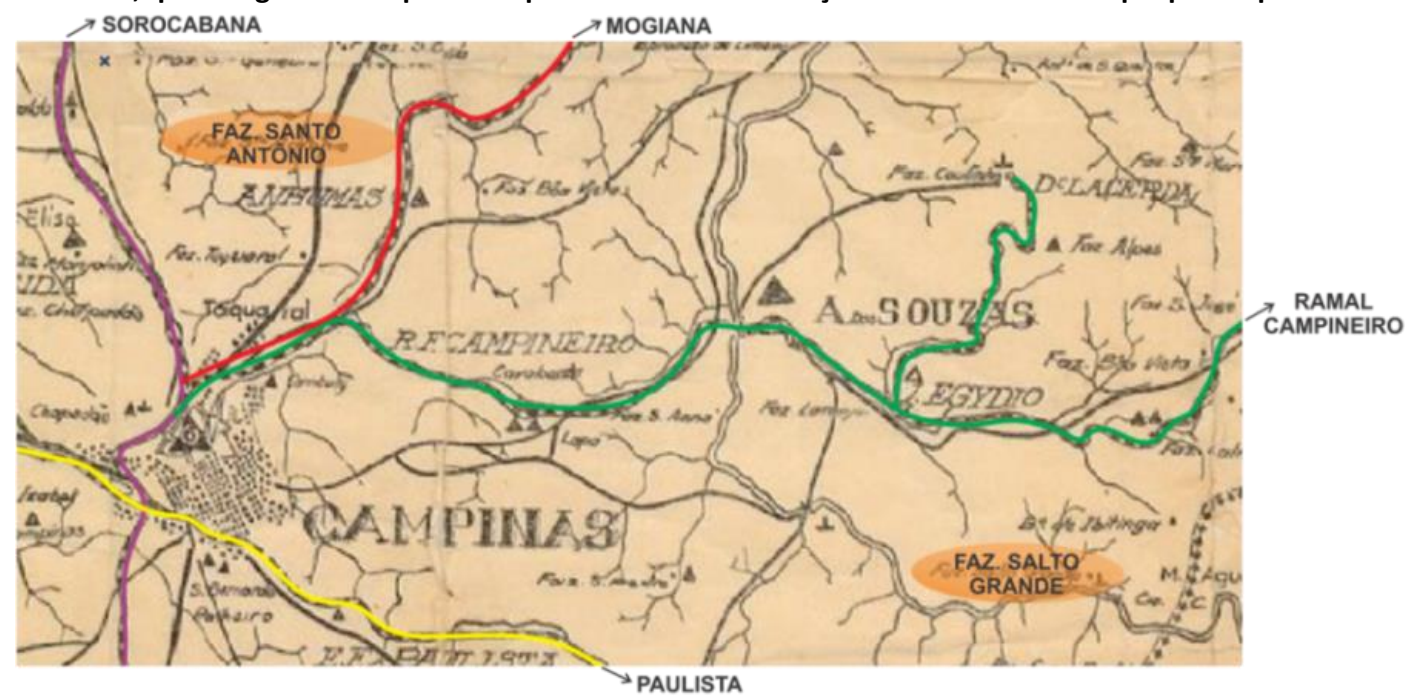

Fonte: Mapa base disponível em: <

https://upload.wikimedia.org/wikipedia/commons/6/60/Mapa_de_Campinas_de_1929.jpg>. Acesso em: 18 de outubro de 2018. Intervenções elaboradas pelas autoras (2018).

O Campo de Santa Amélia pertencente ao IAE e o anexo a Escola Particular de Agricultura de Campinas, não puderam ser localizados com precisão por faltarem de dados históricos, assim, optou-se por não inseri-los nos mapas.

\section{CONSIDERAÇÕES FINAIS}

Os Campos de Experiência e Demonstração implantados no território paulista estavam ligados a uma política mais ampla que tinha como objetivo principal a modernização da agricultura, por meio da disseminação do conhecimento ao homem do campo e da diversificação da produção agrícola.

O resgate documental das informações contidas nos Relatórios da Secretaria da Agricultura do período estudado permitiu-nos chegar a um total de 30 Campos que puderam ser organizados em quatro diferentes grupos, tendo em vista suas características administrativas (administração do IAE, dos Inspetores Agrícolas diretamente subordinados ao Secretario da Agricultura, das Escolas de Agricultura e do Horto Botânico de São Paulo). Verificou-se que, buscando incentivar a policultura, esses Campos ensaiaram e produziram diferentes culturas, entre elas: espécies agrícolas como o café, o arroz e o trigo; industriais como o algodão; silvícolas como o eucalipto e muitas outras ornamentais, para a arborização de ruas e o embelezamento de jardins. Além disso, a localização desses Campos e sua relação com as linhas férreas existentes revelou a articulação de uma rede, por onde circulavam informações, produtos e pessoas. 
Essa rede viu-se comprometida no ano de 1914 , quando em função da $1^{\circ}$ Guerra Mundial, a situação financeira do Estado foi agravada e por medidas de economia, vários serviços da SACOP foram remodelados e simplificados ${ }^{22}$. Neste momento, alguns Campos foram fechados, somando-se aos que já havia sido desativados no decorrer dos anos, ora por já terem atingido os objetivos para os quais haviam sido propostos, ora por não satisfaze-los. Assim, permaneceram os Campos de: Jardim de Guanabara, Taquaral, Santa Elisa e Monjolinho (administrados pelo IAE); Mogy das Cruzes, Guaratinguetá e Sorocaba (administrados pelos Inspetores de Agricultura); da Escola Agrícola Prática de Piracicaba, das Escolas Municipais de Batatais e Araras (anexos às escolas de agricultura) e o Horto Tropical de Ubatuba (sob a responsabilidade do Horto Botânico de São Paulo); sendo que não foram encontradas informações suficientes para determinar o ano em que deixaram de ser utilizados os Campos: da Escola Prática "Dr. Carlos Botelho", da Escola Prática "Dr. Candido Rodrigues" e das Escolas Agrícolas Particulares, localizadas em Lorena e Campinas.

Imagem 2 e 3: A imagem da esquerda, demonstra a abertura de "regos" por meio do arado de disco puxado por bois no Campo de Moreira Cesar, enquanto a imagem da direita, mostra uma aula pratica da Escola Agrícola Luiz de Queiroz, onde os alunos efetuavam a colheita de algodão nos Campos da Fazenda-Modelo.
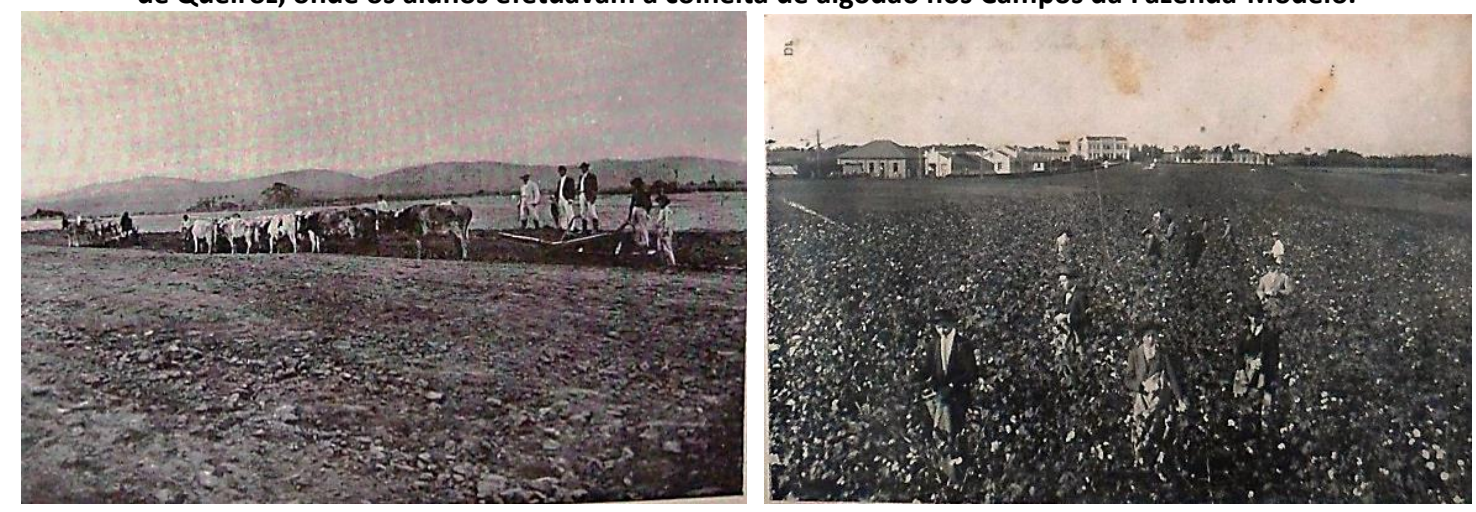

Fonte Imagem 2: Relatório SACOP (1907).

Fonte Imagem 3: Relatório SACOP (1912-1913).

\section{REFERÊNCIAS BIBLIOGRÁFICAS}

CARMO, V.; ALVIM, Z. Chão Fecundo: 100 anos de História do Instituto Agronômico de Campinas. S/Ed, 1987.

Revista Agrícola. Órgão da Sociedade Pastoril e Agrícola. 1898.

SÃO PAULO (Estado). Relatório da Secretaria dos Negócios da Agricultura, Comércio e Obras Públicas. 1895-1916.

SÃO PAULO. Relatório Anual do Instituto Agronômico de Campinas. Campinas, 1892-1893.

22 Lei $n^{\circ} 1455$ de 29 de Dezembro de 1914. Disponível em: < https://www.al.sp.gov.br/repositorio/legislacao/lei/1914/lei-1455-29.12.1914.html>. Acesso em 27 de outubro de 2018. 


\section{Revista Nacional de}

Gerenciamento de Cidades

National Journal of Cities Management

VERSIEUX, D.P.; GONÇALVES, I. A. A criação das fazendas-modelo em Minas Gerais: uma política pública para a educação profissional agrícola na Primeira Repúblicas (1906-1914). Revista de História Regional. Minas Gerais, vol. 18, p. 125-151, 2013. Disponível em: <http://www.revistas2.uepg.br/index.php/rhr/article/view/3346/3514>. Acesso em: 01 de outubro de 2018.

\section{SITES CONSULTADOS}

Estações Ferroviárias do Brasil. Disponível em: <http://www.estacoesferroviarias.com.br>. Acesso em: diversas datas.

Assembleia Legislativa do Estado de São Paulo. Disponível em: < https://www.al.sp.gov.br/>. Acesso em: diversas datas. 